\title{
Influence of activated charcoal, porcine gastric mucin and $\beta$-cyclodextrin on the morphology and growth of intestinal and gastric Helicobacter spp.
}

\author{
Jalal Taneera, ${ }^{1}$ Anthony P. Moran, ${ }^{2}$ Sean O. Hynes, ${ }^{1}$ Hans-Olof Nilsson, ${ }^{1}$ \\ Waleed abu Al-Soud ${ }^{1}$ and Torkel Wadström ${ }^{1}$
}

1 Department of Medical Microbiology, Dermatology and Infection, Lund University, Lund Sölvegatan 23, SE-22362, Sweden

2 Department of Microbiology, National University of Ireland, Galway, Ireland

\author{
Author for correspondence: Anthony P. Moran. Tel: +353 91524411 ext 3163. Fax: +35391525700. \\ e-mail: anthony.moran@nuigalway.ie
}

\begin{abstract}
Bile-tolerant Helicobacter spp. are emerging human and animal pathogens. However, due to their fastidious nature, which requires nutrient-rich complex media to grow, infection with these bacteria may be underestimated. The accumulation of toxic metabolites in cultures may be one of the main obstacles for successful culture of these organisms. The present study examined various potential growth-enhancing substances for Helicobacter spp. and, furthermore, how they may affect spiral to coccoid conversion. Five Helicobacter spp. were cultured on agar and in broth media supplemented with activated charcoal, $\beta$-cyclodextrin, or porcine gastric mucin. Growth was determined by estimating the numbers of colony-forming units and colony diameter, as well as bacterial cell mass. Coccoid transformation was estimated every $24 \mathrm{~h}$ by both Gram and acridine-orange staining. Activated charcoal was superior in supporting growth and increased cell mass on agar and in broth media. $\beta$-Cyclodextrin delayed spiral to coccoid conversion by Helicobacter pylori and Helicobacter canis, whereas activated charcoal delayed the conversion to coccoid forms of Helicobacter hepaticus and Helicobacter bilis. The progression to coccoid forms by Helicobacter pullorum on agar media was not influenced by any growth supplement. The spiral to coccoid conversion was more rapid in broth media than on agar media. The growth enhancement observed is probably related to the capacity of activated charcoal to remove toxic compounds in culture media.
\end{abstract}

Keywords: Helicobacter pylori, coccoid forms, coccoid conversion, culture media

\section{INTRODUCTION}

Helicobacter pylori is known to be the causative agent of chronic gastritis and peptic ulcer disease (Goodwin et al., 1997), as well as being associated with the development of gastric cancer (Forman, 1996). Since the original isolation of $H$. pylori in 1982, the genus Helicobacter has been expanded to include more than 20 identified species isolated from the gastrointestinal tract and liver of man and various animals (Versalovic \& Fox, 2001), including dogs (Fox et al., 1996; Jalava et al., 1997), cats (Norris et al., 1999), mice (Ward et al., 1994; Fox et al., 1995), rodents (Lee et al., 1992), poultry (Stanley et al., 1994), hamsters (Franklin et al., 1996) and

Abbreviation: CCUG, Culture Collection of the University of Gothenburg. cheetahs (Eaton et al., 1993). These novel helicobacters have been associated with the development of various gastrointestinal disorders in their respective hosts.

However, despite being isolated from an ever-increasing number of hosts, most Helicobacter spp. remain difficult to culture from clinical samples. Various solid and broth culture media have been designed to optimize growth for the production of various antigens (Shahamat et al., 1991; Marchini et al., 1995; Walsh \& Moran, 1997), to facilitate metabolic and enzyme studies, and to prevent accumulation of toxic metabolites that inhibit growth in the stationary phase (Hazell et al., 1989). However, culture media for Helicobacter spp. remain poorly developed with the exception of H.pylori.

In addition, the related phenomenon of spiral to coccoid conversion has been investigated in H. pylori (Donelli et 
al., 1998; Worku et al., 1999) but not in other helicobacters. H. pylori cells may exist in two morphological variants (Benaissa et al., 1996): a bacillary form with a spiral or helical shape and a coccoid form which usually appears after several days of culture. This conversion generally occurs after 6-10 days of culture in stationary phase (Chan et al., 1994; Benaissa et al., 1996). Several factors may influence the spiral to coccoid conversion by $H$. pylori, such as acid $\mathrm{pH}$ stress, oxygen, temperature, nutritional starvation (West et al., 1990; Cellini et al., 1994; Donelli et al., 1998; Worku et al., 1999) and, thus, potentially culture media composition may influence the rate of spiral to coccoid conversion by Helicobacter spp. It has been speculated that the conversion to coccoid forms may be important for maintaining viability and survival of $H$. pylori outside the host (West et al., 1990), as well as in recrudescence of infection and treatment failure of patients with peptic ulcer disease (Benaissa et al., 1996). On the other hand, other microaerophilic bacteria produce non-culturable coccoid forms resembling those of helicobacters (Moran, 1997) and these have been shown to be a degenerate cell form which is undergoing cellular degradation (Moran \& Upton, 1986) in response to oxygen toxicity and metabolites in culture media (Moran \& Upton, 1987a, b). Likewise, compared to spiral forms, it has been shown that coccoid forms of $H$. pylori have impaired genomic DNA, total amounts of DNA and RNA are reduced, there is loss of membrane potential, and levels of intracellular ATP, indicative of metabolic state, are significantly reduced, collectively indicating a process of cellular degeneration (Kusters et al., 1997; Moran, 1997; Narikawa et al., 1997).

The present study was undertaken to establish optimized culture media for the growth of Helicobacter hepaticus, Helicobacter bilis, Helicobacter pullorum and Helicobacter canis through the addition of $\beta$-cyclodextrin, porcine mucin and activated charcoal, using $H$. pylori for comparison. Improvements in the ability to culture these emerging pathogens would allow a more precise diagnosis of infection. Furthermore, we also examined the effect of culture conditions on the conversion of spiral to non-culturable coccoid forms.

\section{METHODS}

Bacterial strains. A number of helicobacters were examined in the present study, including two $H$. pylori clinical isolates (BH43 and G50) from the Clinical Bacteriology Laboratory, University Hospital, Lund, Sweden. The H. pylori type strain (CCUG 17874), H. pullorum (CCUG 33838), and H. bilis (CCUG 38995) were purchased from the Culture Collection of the University of Gothenburg (CCUG), Gothenburg, Sweden, whereas H. canis (NCTC 12739) and H. hepaticus (NCTC 12886) were from the National Collection of Type Cultures, Colindale, UK. All bacteria were maintained at $-70{ }^{\circ} \mathrm{C}$ in tryptic soy broth supplemented with $15 \%$ (v/v) glycerol.

Agar media composition and culture conditions. Two types of agar media were used in the present study: (i) GAB-Camp agar (GCA) for culturing H. pylori (Soltesz et al., 1992), and (ii) Brucella agar (BA) (Becton Dickinson) to culture $H$. bepaticus, H. pullorum, H. canis and $H$. bilis. These media were modified by supplementation with $5 \%(\mathrm{v} / \mathrm{v})$ sheep blood, $5 \%(\mathrm{v} / \mathrm{v})$ inactivated horse serum (Gibco-BRL), 1\% (v/v) IsoVitalex (Becton Dickinson) and 1\% (v/v) haemin. Each strain was cultured on GCA or BA without antibiotics as indicated above at $37^{\circ} \mathrm{C}$ for $2-4$ days under microaerobic conditions $\left(5 \% \mathrm{O}_{2}, 5 \% \mathrm{CO}_{2}, 4 \% \mathrm{H}_{2}\right.$ and $81 \% \mathrm{~N}_{2}$; or $10 \%$ $\mathrm{O}_{2}, 5 \% \mathrm{CO}_{2}$ and $85 \% \mathrm{~N}_{2}$ ) and subcultured under the same conditions. Colonies were harvested, suspended in normal saline and adjusted to an $\mathrm{OD}_{540}$ of $1 \cdot 0$, equivalent to a concentration of $5 \times 10^{8}$ c.f.u. $\mathrm{ml}^{-1}$, which was subsequently diluted, to a density of $10^{4}$ c.f.u. $\mathrm{ml}^{-1}$ for each strain. An aliquot of this dilution $(100 \mu \mathrm{l})$ was applied to agar media containing different supplements. These included various concentrations of 2,6-di-O-methylcyclodextrin (Cyclolab, Budapest, Hungary), porcine gastric mucin (type III from porcine stomach) (Sigma) and two types of activated charcoal added, with particle sizes of $1.2 \mathrm{~mm}$ (Sigma) and 2-4 mm (Rudolph Grave-Stockholm, Sweden) (Table 1). The 2,6-di-O-methylcyclodextrin was filter-sterilized before addition to sterile media, whereas activated charcoal and porcine mucin were added prior to autoclaving at $121^{\circ} \mathrm{C}$ for $20 \mathrm{~min}$. The suitability of each medium for each Helicobacter spp. was evaluated by measuring both the number of c.f.u. in triplicate and the mean diameters of the colonies. All inoculations were performed in duplicate and evaluations of each medium were repeated.

Broth media and culture conditions. Two types of broth media were used in the present investigation. Gonococcal broth (GB) originally described for culturing Neisseria gonorrhoeae (Soltesz \& Mårdh, 1980), was used to culture $H$. pylori, whereas brain heart infusion broth (BHI) was used for the culture of $H$. bilis, H. canis, H. hepaticus and H. pullorum. Standard broth media contained $7 \%(\mathrm{v} / \mathrm{v})$ inactivated horse serum, $1 \%(\mathrm{v} / \mathrm{v})$ IsoVitalex, $1 \%(\mathrm{v} / \mathrm{v})$ haemin and $0.6 \%$ $(\mathrm{w} / \mathrm{v})$ yeast extract. All broth media were inoculated using two volumes of cells $(5 \mu \mathrm{l}$ each) harvested from solid media using a loop with a $5 \mathrm{~mm}$ diameter (Sarstedt) and deposited into a $100 \mathrm{ml}$ Erlenmeyer flask containing $50 \mathrm{ml} \mathrm{GB}$ or BHI. The flasks containing media were incubated at $37^{\circ} \mathrm{C}$ in anaerobic jars on a rotary shaker (150 r.p.m.) under microaerobic conditions generated by an AnaerocultC envelope without palladium catalyst, which produced a final atmosphere containing 5-6\% $\mathrm{O}_{2}$ and $8-10 \% \mathrm{CO}_{2}$ (Merck). After incubation for 2 days, $1 \mathrm{ml}$ of each culture was subcultured into GB or BHI supplemented with different concentrations of activated charcoal, porcine gastric mucin or $\beta$-cyclodextrin (see Table 1) under the same conditions as described above. To determine the number of c.f.u. $\mathrm{ml}^{-1}$, cultures were serially diluted in $0 \cdot 15 \mathrm{M}$ PBS $\mathrm{pH} 7 \cdot 2$, with strains enumerated in triplicate, by plating onto GCA or BA medium under microaerobic conditions as described above. All inoculations were performed in duplicate and evaluations of each medium were repeated.

Calculation of percentage of coccoid forms. Bacterial cells from both agar and broth media were examined by Gram and acridine-orange staining at a magnification of $1000 \times$, at $24 \mathrm{~h}$ intervals. Duplicate sets of inoculated media were examined. The percentage of cells with spiral or coccoid morphology was estimated microscopically by counting 100 cells in two samples of each bacterial suspension (all data are shown as the mean percentage). Bacterial cells were stained using standard Gramstaining techniques and also acridine-orange staining. Prior to either staining, cells were suspended to a standard $\mathrm{OD}_{540}$ of $1 \cdot 0$. For acridine-orange staining, cells $(1 \mu \mathrm{l})$ were mixed with $9 \mu \mathrm{l}$ acridine orange $\left(1 \cdot 0 \mathrm{mg} \mathrm{PBS} \mathrm{ml}^{-1}, \mathrm{pH} 7 \cdot 2\right)$ on a microscope 
Table 1. Solid culture media composition and their effect on five Helicobacter spp.

Results shown are mean values \pm standard deviation from duplicate experiments whose determinations were repeated in triplicate.

\begin{tabular}{|c|c|c|c|c|c|c|c|c|c|}
\hline \multirow[t]{3}{*}{ Growth indicator } & \multirow{3}{*}{ Helicobacter sp. } & \multicolumn{8}{|c|}{ Supplements } \\
\hline & & \multicolumn{2}{|c|}{$\boldsymbol{\beta}$-Cyclodextrin } & \multicolumn{2}{|c|}{ Charcoal* } & \multirow{2}{*}{$\begin{array}{l}\text { Charcoal } \dagger \\
0 \cdot 1 \%(w / v)\end{array}$} & \multirow{2}{*}{$\begin{array}{c}\text { Mucin } \neq \\
0 \cdot 1 \%(v / v)\end{array}$} & \multirow{2}{*}{$\begin{array}{l}\text { Control } \\
\text { media } \$\end{array}$} & \multirow{2}{*}{$\begin{array}{l}\text { Control media } \\
\text { without blood }\end{array}$} \\
\hline & & $0 \cdot 1 \%(w / v)$ & $0.2 \%(w / v)$ & $0 \cdot 1 \%(w / v)$ & $0 \cdot 2 \%(w / v)$ & & & & \\
\hline \multirow[t]{7}{*}{ Colony numbers (c.f.u. $\mathrm{ml}^{-1}$ ) } & H. pylori (CCUG 17874) & $60 \pm 119$ & $52 \pm 7$ & $70 \pm 11$ & $60 \pm 119$ & $63 \pm 109$ & $50 \pm 9$ & $50 \pm 11$ & $20 \pm 99$ \\
\hline & H. pylori (BH43) & $55 \pm 11$ & $46 \pm 6$ & $63 \pm 109$ & $56 \pm 99$ & $58 \pm 99$ & $43 \pm 8$ & $47 \pm 11$ & $11 \pm 59$ \\
\hline & H. pylori (G50) & $40 \pm 8$ & $50 \pm 5$ & $50 \pm 8$ & $41 \pm 79$ & $45 \pm 79$ & $35 \pm 6$ & $31 \pm 7$ & $9 \pm 49$ \\
\hline & H. canis (NCTC 12739) & $90 \pm 5$ & $98 \pm 8$ & $120 \pm 69$ & $112 \pm 69$ & $110 \pm 3$ & $110 \pm 17$ & $100 \pm 6$ & $12 \pm 79$ \\
\hline & H. hepaticus (NCTC 12886)\| & ++ & ++ & +++ & +++ & +++ & ++ & ++ & - \\
\hline & H. pullorum (CCUG 33838) & $75 \pm 14$ & $75 \pm 20$ & $93 \pm 109$ & $86 \pm 99$ & $89 \pm 19$ & $75 \pm 7$ & $75 \pm 7$ & $25 \pm 149$ \\
\hline & H. bilis (CCUG 38995) & $60 \pm 5$ & $59 \pm 8$ & $78 \pm 59$ & $75 \pm 3$ & $75 \pm 1$ & $63 \pm 8$ & $65 \pm 9$ & $25 \pm 149$ \\
\hline \multirow[t]{6}{*}{ Colony diameter (mm) } & H. pylori (CCUG 17874) & $1 \cdot 2$ & $1 \cdot 2$ & $1 \cdot 4$ & $1 \cdot 4$ & $1 \cdot 4$ & $1 \cdot 0$ & $1 \cdot 0$ & 0.5 \\
\hline & H. pylori (BH43) & $1 \cdot 2$ & $1 \cdot 2$ & $1 \cdot 4$ & $1 \cdot 4$ & $1 \cdot 4$ & $1 \cdot 0$ & $1 \cdot 0$ & $0 \cdot 5$ \\
\hline & H. pylori (G50) & $1 \cdot 0$ & $1 \cdot 0$ & $1 \cdot 5$ & $1 \cdot 5$ & $1 \cdot 5$ & $1 \cdot 2$ & $1 \cdot 0$ & $0 \cdot 7$ \\
\hline & H. canis (NCTC 12739) & $0 \cdot 8$ & $0 \cdot 8$ & $1 \cdot 0$ & $0 \cdot 8$ & $0 \cdot 8$ & $0 \cdot 8$ & $0 \cdot 8$ & $0 \cdot 5$ \\
\hline & H. pullorum (CCUG 33838) & $0 \cdot 8$ & $0 \cdot 8$ & $1 \cdot 0$ & $1 \cdot 0$ & $1 \cdot 0$ & $0 \cdot 8$ & $0 \cdot 8$ & $0 \cdot 5$ \\
\hline & H. bilis (CCUG 38995) & $0 \cdot 8$ & $0 \cdot 8$ & $1 \cdot 0$ & $1 \cdot 0$ & $1 \cdot 0$ & $0 \cdot 8$ & $0 \cdot 8$ & $0 \cdot 5$ \\
\hline
\end{tabular}

* Media supplemented with activated charcoal having a diameter of $1.2 \mathrm{~mm}$.

† Media supplemented with activated charcoal having a diameter of 2-4 $\mathrm{mm}$.

$\ddagger$ Media supplemented with porcine gastric mucin.

SControl media were without any additional supplements: GCA for H. pylori or BA for bile-tolerant species.

$\| H$. hepaticus was plated semi-quantitatively and assessed as: - , no growth; + , poor growth; ++ , good growth;,+++ very good growth.

I $P<0.05$ and considered significantly different from control media, using the Mann-Whitney $U$-test.

slide, and immediately examined under a fluorescent microscope (Zeiss Axioskop G 42-110e).

Cell lysate. The protein content of cells harvested from broth media, supplemented with activated charcoal, $\beta$-cyclodextrin, or porcine gastric mucin, was examined as an indication of growth enhancement. Cells $(5 \mathrm{ml})$ grown in broth media were collected following $72 \mathrm{~h}$ culture, washed in PBS and lysed by sonication in an ice bath, with $50 \%$ of pulse at $30 \mathrm{~s}$ intervals for $4 \mathrm{~min}$ (Labsonic U, B. Braun Diessel Biotech Inc.). Following centrifugation $\left(12000 \mathrm{~g}, 20 \mathrm{~min}, 4^{\circ} \mathrm{C}\right)$, the protein content of the cell-free fractions was determined using a Coomassie brilliant blue protein assay (G250 dye reagent, Bio-Rad). Duplicate sets of broth media were inoculated and, hence, determinations of protein content were made on two independent samples.

Electron microscopy. Cells were prefixed by application of $2.5 \%$ glutaraldehyde directly to agar plates. Subsequently, the cells on the plates were rinsed three times with Millonig phosphate buffer. A portion of growth equivalent to $1 \mathrm{~cm}^{2}$ was then removed from the agar plate and transferred to a sterile container. The colonies were dehydrated with $25 \%, 50 \%$, $75 \%$ and $98 \%$ ethanol $(2 \times 20 \mathrm{~min})$ respectively, followed by an overnight dehydration step with absolute ethanol, and were subsequently freeze-dried. The cells were mounted on metal stubs and sputter coated using gold/palladium. The samples were examined in a Philips 515 scanning electron microscope.

Statistical anlaysis. For analysis of quantitative growth in various media and comparison of independent groups of data, the Mann-Whitney U-test was used. The Tukey-Kramer multiple comparisons test was applied when comparing the level of protein content in supplemented and control media. A value of $P<0.05$ was considered significant.

\section{RESULTS}

\section{Growth and coccoid forms of $\boldsymbol{H}$. pylori on agar media}

All H. pylori strains were able to grow in the presence or absence of hydrogen gas. However, in the presence of $4 \%$ hydrogen, growth was visible after $48 \mathrm{~h}$ compared to $60 \mathrm{~h}$ in its absence. The highest c.f.u. numbers and the largest colony diameter $(1.4 \mathrm{~mm})$ for $H$. pylori after 4 days of growth were observed on the GCA medium supplemented only with $0 \cdot 1 \%(\mathrm{w} / \mathrm{v})$ activated charcoal (diameter $1.2 \mathrm{~mm}$ ), whereas the lowest c.f.u. numbers and the smallest colony diameter $(0.5 \mathrm{~mm})$ were observed on GCA blood-free media, compared to $1.0 \mathrm{~mm}$ on control media (Table 1). Moreover, the numbers of c.f.u. on charcoal-supplemented media for the three H. pylori strains were significantly higher $(P<0.05)$ and those on blood-free media were significantly lower $(P<0.05)$ than on control media. GCA supplemented with porcine gastric mucin did not affect growth of $H$. pylori, compared to control media. The colony diameter was increased when cells began to switch to coccoid forms after 8-9 days of growth. As shown in Fig. 1(a), the spiral to coccoid conversion by $H$. pylori started on day 7 , independent of the growth supplement used, with the exception of cells grown on GCA blood-free agar, where the conversion started on day 8. Microscopic examination revealed a complete conversion to coccoid forms by day 11 on both control media and GCA supplemented with porcine gastric mucin. However, a complete spiral to coccoid conversion on GCA supplemented with activated charcoal occurred on day 13 and 
with $\beta$-cyclodextrin on day 14 . On blood-free agar, the coccoid morphology was dominant following 16 days of culture.

\section{Growth and coccoid forms of $\boldsymbol{H}$. pylori in broth culture}

H. pylori cultured in GB supplemented only with $0 \cdot 1 \%$ $(\mathrm{w} / \mathrm{v})$ activated charcoal showed the highest numbers of c.f.u. $\mathrm{ml}^{-1}$, whereas control media or GB supplemented with porcine gastric mucin yielded the lowest numbers of c.f.u. (Fig. 2a). Compared to control media, the number of c.f.u. in charcoal-supplemented broth was significantly higher $(P<0.05)$ at day 2 and on subsequent days of incubation, but was not significantly different $(P>0.05)$ in the other supplemented media. The conversion to coccoid forms began in all supplemented media on day $3 ; 10 \%$ of the total cell numbers were converted to coccoid forms on day 3 , whereas on day 4 this had increased to approximately $30 \%$. In control media or GB supplemented with porcine gastric mucin, approximately $80 \%$ of the cells were converted to coccoid forms on day 6 , with a complete conversion recorded after 7 days of culture. Around $60 \%$ of bacterial cells grown in GB supplemented with $0 \cdot 1 \%$ $(\mathrm{w} / \mathrm{v})$ activated charcoal or $\beta$-cyclodextrin were coccoid forms on day 6 of culture, and $80 \%$ and $75 \%$ by day 7 , respectively. Complete conversion occurred on day 8 in GB supplemented with activated charcoal, and on day 9 in GB supplemented with $\beta$-cyclodextrin. As shown in Table 2, the results of the total protein assay revealed that $H$. pylori cultured in GB supplemented with activated charcoal had the highest protein content, when compared to other supplements. Furthermore, the protein content of $H$. pylori grown in charcoal-supplemented media was significantly higher $(P<0.01)$ than that grown in control media.

\section{Growth and coccoid forms of bile-tolerant Helicobacter spp. on agar media}

Several differences were noted in the growth characteristics of the Helicobacter spp. tested on agar media. In contrast to $H$. hepaticus and $H$. pullorum, which both demonstrated notable growth after $24 \mathrm{~h}$ of incubation, H. pylori, H. canis and H. bilis exhibited notable growth only after $48-72 \mathrm{~h}$ of incubation. Only $H$. canis was able to grow in the absence of hydrogen. At a low cell inoculum $\left(10^{-7}, 10^{-8}\right.$ dilution) no growth was obtained with $H$. hepaticus. In general, the lowest c.f.u., which differed significantly $(P<0.05)$ from the number of c.f.u. on control media, as well as the smallest colony diameters were obtained on BA blood-free agar and, moreover, no growth of $H$. hepaticus occurred on such media (Table 1). Supplementation of the blood-free media with $0 \cdot 1 \%(\mathrm{w} / \mathrm{v})$ activated charcoal or $0 \cdot 1 \%$ $(\mathrm{w} / \mathrm{v}) \beta$-cyclodextrin did not influence growth (data not shown). Also, similar to $H$. pylori, supplementation with $0 \cdot 1 \%(\mathrm{w} / \mathrm{v})$ activated charcoal (diameter $1.2 \mathrm{~mm}$ ) gave the highest c.f.u. and the largest colony diameter, compared to the other supplements of $\beta$-cyclodextrin or

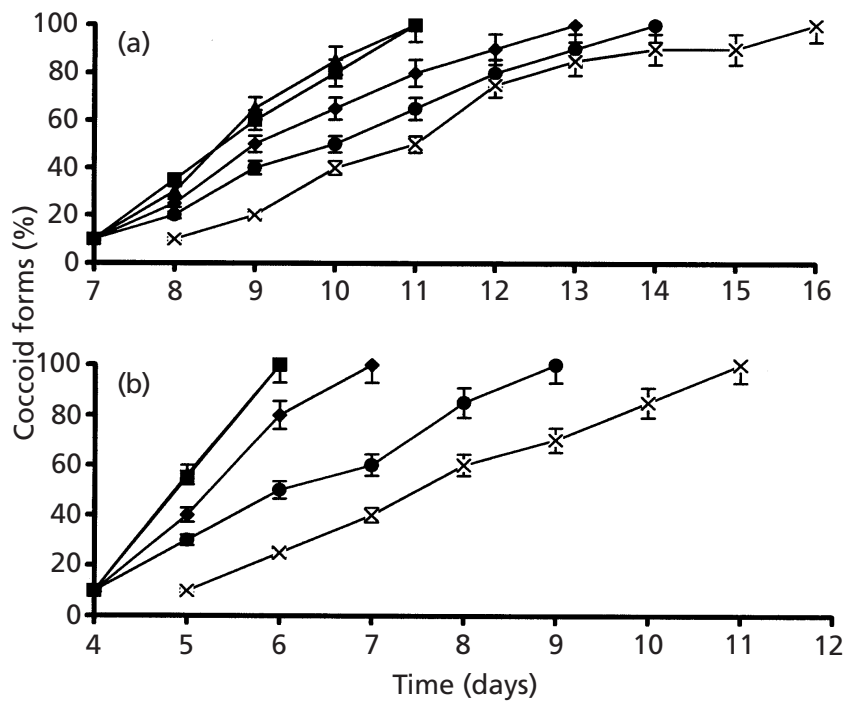

Fig. 1. Influence of various supplements in agar media on the conversion rate of spiral to coccoid forms by $H$. pylori CCUG 17874 (a) and $H$. canis NCTC 12739 (b) when grown on media supplemented with $0.1 \%(\mathrm{w} / \mathrm{v}) \beta$-cyclodextrin (O), $0.1 \%(\mathrm{w} / \mathrm{v})$ activated charcoal having a diameter of $1.2 \mathrm{~mm}(\diamond)$ or $0.1 \%$ $(\mathrm{v} / \mathrm{v})$ porcine gastric mucin $(\boldsymbol{\Delta})$, compared to when grown without any of these supplements $(\boldsymbol{\square})$ and in blood-free agar media $(x)$. Bars indicate standard deviations of the means.

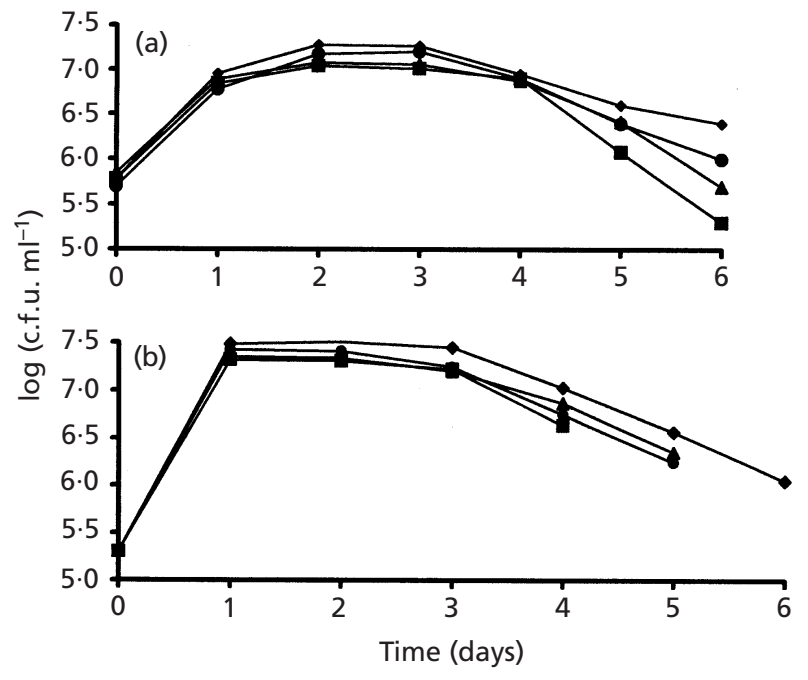

Fig. 2. Influence of various supplements on the growth kinetics in broth of $H$. pylori CCUG 17874 (a) and H. canis NCTC 12739 (b) when grown on media supplemented with $0.1 \%(\mathrm{w} / \mathrm{v})$ $\beta$-cyclodextrin (O), $0.1 \%(\mathrm{w} / \mathrm{v})$ activated charcoal having a diameter of $1.2 \mathrm{~mm}(\diamond)$ or $0.1 \%(\mathrm{v} / \mathrm{v})$ porcine gastric mucin $(\boldsymbol{\Delta})$, compared to when grown without any of these supplements (ם).

porcine gastric mucin (Table 1). Furthermore, the number of c.f.u. on charcoal-supplemented media was significantly higher $(P<0.05)$ than on control media. The colony size was about $0 \cdot 8-1 \cdot 0 \mathrm{~mm}$, except for colonies on BA blood-free agar media, where colonies 
Table 2. Total protein content $\left(\mu \mathrm{g} \mathrm{ml}^{-1}\right)$ extracted from helicobacter cells after $48 \mathrm{~h}$ growth on media with various supplements

Results shown are mean values \pm standard deviation from duplicate experiments.

\begin{tabular}{|c|c|c|c|c|}
\hline \multirow[t]{2}{*}{ Helicobacter sp. } & \multicolumn{4}{|c|}{ Supplements } \\
\hline & $\begin{array}{c}0 \cdot 1 \%(w / v) \\
\text { Cyclodextrin }\end{array}$ & $\begin{array}{c}0.1 \%(w / v) \\
\text { Charcoal* }\end{array}$ & $\begin{array}{c}0 \cdot 1 \%(w / v) \\
\text { Mucin } \dagger\end{array}$ & Control media $\neq$ \\
\hline H. pylori CCUG 17874 & $184 \pm 3$ & $206 \pm 7 \mathbb{S}$ & $170 \pm 5$ & $170 \pm 5$ \\
\hline H. pylori $\mathrm{BH} 43$ & $175 \pm 5 \cdot 5$ & $196 \pm 5 \cdot 5 \mathbb{S}$ & $165 \pm 4 \cdot 5$ & $162 \pm 3 \cdot 5$ \\
\hline H. pylori G50 & $162 \pm 3 \cdot 5 \|$ & $179 \pm 5 \mathbb{S}$ & $162 \pm 3 \|$ & $136 \pm 5$ \\
\hline H. canis NCTC 12739 & $175 \pm 5$ & $201 \pm 8 \mathbb{S}$ & $162 \pm 3 \cdot 5$ & $162 \pm 3 \cdot 4$ \\
\hline H. bilis CCUG 38995 & $180 \pm 5$ & $199 \pm 4 \cdot 5 \|$ & $177 \pm 4$ & $175 \pm 5$ \\
\hline
\end{tabular}

* Media supplemented with activated charcoal having a diameter of $1.2 \mathrm{~mm}$.

† Media supplemented with porcine gastric mucin.

$\ddagger$ Control media were without any additional supplements: GCA for H. pylori or BA for bile-tolerant species.

$\mathbb{S} P<0 \cdot 01$ and considered significantly different from control media, using the Tukey-Kramer multiple comparisons test.

$\| P<0.05$ and considered significantly different from control media, using the Tukey-Kramer multiple comparisons test.

had a diameter $<0.6 \mathrm{~mm}$. The colony diameter of biletolerant Helicobacter spp. as well as H. pylori increased when spiral forms began to convert to coccoid forms.

As shown in Fig. 1(b), the conversion of H.canis started on day 4 on various agar media. On control media and BA supplemented with porcine gastric mucin, conversion to coccoid forms was complete after 6 days of culture, whereas the conversion was complete on BA supplemented with activated charcoal on day 7 and on BA supplemented with $\beta$-cyclodextrin on day 9. On the other hand, on BA blood-free agar, coccoid forms were dominant only at day 11 .

On control media, $20 \%$ coccoid forms occurred after 2 days of culture of $H$. pullorum and spiral to coccoid conversion was complete on day 4 . On supplemented media, the transformation from spiral to coccoid forms by $H$. pullorum appeared on day 4 with $15 \%$ coccoid forms; on days 5 and 6 the percentages of coccoid forms were $40 \%$ and $75 \%$, respectively. The spiral to coccoid conversion was complete on day 7 on all supplemented agar media, and on BA blood-free agar 1 day later.

The conversion to coccoid forms by $\mathrm{H}$. bilis on all agar media started on day 7 with $10 \%$ coccoid forms occurring. In BA control media, BA with activated charcoal, and BA blood-free agar, the spiral to coccoid conversion occurred at a conversion rate of $5 \%$ daily and was complete after 26 days of culture. Although the conversion on BA supplemented with $\beta$-cyclodextrin or porcine gastric mucin began similarly after 7 days of culture, the daily conversion rate was higher $(7 \%)$ and was complete after 21 days of incubation. The spiral to coccoid conversion by $H$. hepaticus occurred 1 day after appearance of visible colonies and was complete on control media and BA supplemented with $\beta$-cyclodextrin 2 days later. On BA supplemented with activated charcoal, complete conversion to coccoid forms occurred after one further day.

\section{Growth and coccoid forms of bile-tolerant Helicobacter spp. in broth culture}

Unlike the other helicobacters examined, $H$. canis was successfully subcultured from BHI. Moreover, H. canis grown on BHI supplemented with $1 \%(\mathrm{w} / \mathrm{v})$ activated charcoal gave higher numbers of c.f.u. $\mathrm{ml}^{-1}$ (Fig. 2b) and the highest protein content (Table 2) compared to the other media. This protein content was significantly greater $(P<0.01)$ than that of cells grown on control media. In addition, compared to control media, the number of c.f.u. in charcoal-supplemented broth was significantly higher $(P<0.05)$ at day 2 and on subsequent days of incubation, but was not significantly different $(P>0.05)$ in the other supplemented media. Approximately $20 \%$ of the total bacterial cells examined in control media and BHI supplemented with porcine gastric mucin had converted completely to coccoid forms after 2 days of culture, and 1 day later the coccoid percentage had increased to $60 \%$ and $50 \%$, respectively. Complete conversion occurred in both media by day 4 . In BHI supplemented with activated charcoal, the spiral to coccoid conversion started after 3 days of incubation, when $20 \%$ coccoid forms occurred, and was complete on day 6 . In BHI supplemented with $\beta$-cyclodextrin, the conversion started on day 3 , when $20 \%$ coccoid forms 
were present; $50 \%$ coccoid forms occurred on day 5 , and conversion was complete after 7 days of culture.

$H$. pullorum and $H$. hepaticus began conversion with $20 \%$ coccoid forms after 2 days of culture; $60 \%$ coccoid forms were present at day 3 in all media, except that supplemented with $1 \%(\mathrm{w} / \mathrm{v})$ activated charcoal, where $40 \%$ coccoid forms were present. Moreover, 1 day later, conversion to coccoid forms was complete in all media except for that supplemented with charcoal, where conversion to coccoids was complete on day 5 . The spiral to coccoid conversion of $H$. bilis in BHI supplemented with $\beta$-cyclodextrin or porcine mucin was slow compared to the other species; it began on day 4 and was complete on day 8 of incubation. In control media and BHI supplemented with activated charcoal, coccoid forms predominated after 12 days, whereas in BHI supplemented with porcine mucin or $\beta$-cyclodextrin the spiral to coccoid conversion started on day 4 and finished on day 8. Moreover, compared to growth on other supplemented media, $H$. bilis cultured on charcoalsupplemented media had the highest protein content, and this was significantly higher $(P<0.05)$ than that obtained when $H$. bilis was cultured in control media (Table 2).

\section{DISCUSSION}

Helicobacter spp. are capable of colonizing a range of environmental niches in the gastrointestinal tract of many mammalian species (Lee et al., 1992; Stanley et al., 1994; Franklin et al., 1996; Norris et al., 1999). Moreover, a number of species are known to infect the liver and bile tree (Ward et al., 1994; Fox et al., 1995; Versalovic \& Fox, 2001) and others, such as $H$. pullorum and $H$. canis, may cause zoonotic infections in humans (Fox et al., 1998; Nilsson et al., 2000a, b). Since such bile-tolerant Helicobacter spp. are difficult to culture, we attempted in the present investigation to establish optimal conditions for culture. Four different formulations of agar and broth media were examined. In addition, these media were supplemented with activated charcoal, $\beta$-cyclodextrin, or porcine mucin. Our results demonstrated that activated charcoal was superior to $\beta$-cyclodextrin or porcine gastric mucin in stimulating growth of all the five species examined. Several studies have shown that activated charcoal promotes the growth of other pathogenic bacteria such as species of Legionella (Edelstein \& Edelstein, 1993), Brucella (Issam et al., 1990) and Bordetella (Hoppe \& Schwaderer, 1989). Furthermore, activated charcoal has been reported to enhance production of the virulence factors of Listeria monocytogenes in vitro (Ermolaeva et al., 1999).

Both activated charcoal and $\beta$-cyclodextrin have no nutrient value and therefore the effect could be related to their ability to remove toxic compounds present in cultures such as hydrogen peroxide and superoxide ions (Marchini et al., 1995; Buck \& Smith, 1987). Moreover, our results indicate that activated charcoal has a higher adsorption capacity than $\beta$-cyclodextrin. The adsorption properties of activated charcoal depend on the number of fine pores giving a large inner surface area for adsorption. This may explain why greater growth enhancement was observed with activated charcoal having a $0.15 \mathrm{~mm}$ pore size than that with a $2-4 \mathrm{~mm}$ pore size.

Mucin preparations have been shown previously to enhance growth of several oral bacteria (Bradshaw et al., 1994) and Bacteroides fragilis (Roberton \& Stanley, 1982). Furthermore, H.pylori has surface mucin-binding proteins, in common with the bile-tolerant Helicobacter strains studied in this investigation (J. Taneera, S. Hynes \& T. Wadström, unpublished data). However, in this study, in contrast to activated charcoal, porcine gastric mucin did not affect the growth kinetics of bile-tolerant Helicobacter spp. Although blood is the major iron source for some micro-organisms and enhances their growth, bile-tolerant Helicobacter spp., with the exception of $H$. hepaticus, were capable of growth on blood-free media. This indicates that blood is not essential for their growth, although it did enhance the growth of all these helicobacters, similar to previous observations with H. pylori (Walsh \& Moran, 1997). Our data also indicated that hydrogen is an essential growth factor for bile-tolerant helicobacters, but the mechanism by which these organisms utilize hydrogen is poorly understood.

Spiral to coccoid conversion has been observed under certain stress conditions for several Gram-negative pathogens such as Vibrio spp., Escherichia coli, Shigella spp., Salmonella enteritidis, Campylobacter spp., Aeromonas spp. and Legionella spp. (Moran \& Upton, 1987a; Barer et al., 1993). Furthermore, culture media supplemented with activated charcoal or $\beta$-cyclodextrin delayed the conversion to coccoid forms by all the helicobacters we examined. In general, a spiral to coccoid conversion was more rapid in broth than on solid media, most likely due to the dissolved toxic substances enhancing the coccoid transformation (Moran \& Upton, 1987b; Coudron \& Statton, 1995). The ability to delay the spiral to coccoid conversion may be beneficial in the production of cell surface antigens for immunodiagnostic tests since such conversion has been shown to induce changes in the cell wall composition of H. pylori and other bacteria (Costa et al., 1999; Signoretto et al., 2000).

Collectively, our data have shown that activated charcoal enhances growth of five Helicobacter spp. to a greater extent than $\beta$-cyclodextrin or porcine gastric mucin in various culture media and, furthermore, a delay in spiral to coccoid conversion was observed in media supplemented with either activated charcoal or $\beta$ cyclodextrin. Thus, addition of charcoal by increasing the growth yields and reducing conversion to coccoid forms could aid diagnostic laboratories in the ability to isolate and grow these helicobacters. Moreover, the ability to delay conversion to coccoid forms in helicobacters would be of benefit to various analyses carried out on these bacteria. Optimal growth conditions which 
would allow routine culturing of pathogenic helicobacters from liver and bile specimens would be important for a diagnosis and correlation with disease which, at present, rely on molecular biology or serological techniques for detection. In addition to improved diagnostics, optimal conditions for subculture of intestinal helicobacters would allow far greater research in this area where, to date, low numbers of isolates from each species have been available for study.

\section{ACKNOWLEDGEMENTS}

This study was supported by grants from the Swedish Medical Research Council (16X04723) to T. W. and from The University Hospital of Lund.

\section{REFERENCES}

Barer, M. R., Gribbon, L. T., Harwood, C. R. \& Nwoguh, C. E. (1993). The viable but non-culturable hypothesis and medical bacteriology. Rev Med Microbiol 4, 183-191.

Benaissa, M., Babin, P., Quellard, N., Pezennec, L., Cenatiempo, Y. \& Faucher, J. L. (1996). Changes in Helicobacter pylori ultrastructure and antigens during conversion from the bacillary to coccoid form. Infect Immun 64, 2331-2335.

Bradshaw, D. J., Homer, K. A., Marsh, P. D. \& Beighton, D. (1994). Metabolic cooperation in oral microbial communities growth on mucin. Microbiology 140, 3407-3412.

Buck, G. E. \& Smith, J. S. (1987). Medium supplementation for growth of Campylobacter pyloridis. J Clin Microbiol 25, 597-599.

Cellini, L., Allocati, N., Di-Campli, E. \& Dainelli, B. (1994). Helicobacter pylori: a fickle germ. Microbiol Immunol 38, 25-30.

Chan, W. Y., Hui, P. K., Leung, K. M., Chow, J., Kwok, F. \& Ng, C.-S. (1994). Coccoid forms of Helicobacter pylori in the human stomach. Am J Pathol 102, 503-507.

Costa, K., Bacher, G., Allmaier, G., Dominguez-Bello, M. G., Engstrand, L., Falk, P., de Pedro, M. A. \& Garcia-del Portillo, F. (1999). The morphological transition of Helicobacter pylori cells from spiral to coccoid is preceded by a substantial modification of the cell wall. J Bacteriol 181, 3710-3715.

Coudron, P. \& Statton, C. W. (1995). Factors effect growth and susceptibility testing of Helicobacter pylori in liquid media. J Clin Microbiol 33, 1028-1030.

Donelli, G., Matarrese, P., Fiorentini, C., Dainelli, B., Taraborelli, T., Di Campli, E., Di Bartolomeo, S. \& Cellini, L. (1998). The effect of oxygen on the growth and cell morphology of Helicobacter pylori. FEMS Microbiol Lett 168, 9-15.

Eaton, K. A., Dewhirst, F. E., Radin, M. J., Fox, J. G., Paster, B. J., Krakowka, S. \& Morgan, D. R. (1993). Helicobacter acinonyx sp. nov., isolated from cheetahs with gastritis. Int J Syst Microbiol 43, 99-106.

Edelstein, P. H. \& Edelstein, M. A. C. (1993). Comparison of three buffers used in the formation of buffer charcoal yeast extract medium. J Clin Microbiol 31, 3329-3330.

Ermolaeva, S., Belyi, Y. \& Tartakovskii, I. (1999). Characteristics of induction of virulence factor expression by activated charcoal in Listeria monocytogenes. FEMS Microbiol Lett 174, 137-141.

Forman, D. (1996). Helicobacter pylori and gastric cancer. Scand J Gastroenterol 251, 48-51.

Fox, J. G., Yan, L., Dewhirst, F. E., Paster, B. J., Shames, B., Murphy, J. C., Hayward, A., Belcher, J. C. \& Mendes, E. N.
(1995). Helicobacter bilis sp. nov., a novel Helicobacter species isolated from bile, liver, and intestine of aged inbred mice. J Clin Microbiol 33, 445-454.

Fox, J. G., Drolet, R., Higgins, R., Messier, S., Yan, L., Coleman, B. E., Paster, P. J. \& Dewhirst, F. E. (1996). Helicobacter canis isolated from dog liver with multifocal necrotizing hepatitis. $J$ Clin Microbiol 34, 2479-2482.

Fox, J. G., Dewhirst, F. E., Shen, Z. \& 8 other authors (1998). Hepatic Helicobacter species identified in bile and gallbladder tissues in Chileans with chronic cholecystitis. Gastroenterology 114, 755-767.

Franklin, C. L., Beckwith, C. S., Livingston, R. S., Riley, L. K., Gibson, S. V., Besch-Williford, C. V. \& Hook, R. R. (1996). Isolation of a novel Helicobacter cholecystus sp. from the gallbladder of Syrian hamsters with cholangiofibrosis and centrilobular pancreatitis. J Clin Microbiol 4, 2952-2958.

Goodwin, C. S., Mendall, M. M. \& Northfield, T. C. (1997). Helicobacter pylori infection. Lancet 349, 265-269.

Hazell, S. L., Markesich, D. C., Evans, D. J. \& Graham, D. Y. (1989). Influence of media supplements on growth and survival of Campylobacter pylori. Eur J Microbiol 8, 597-602.

Hoppe, J. E. \& Schwaderer, J. (1989). Comparison of four media for the isolation of Bordetella pertussis. J Clin Microbiol 27, 1097-1098.

Issam, R., Rand, K. \& Gaskins, D. (1990). Buffered charcoal-yeast extract medium for the isolation of Brucella. J Clin Microbiol 28, 1671-1672.

Jalava, K., Kartinen, M., Utriainen, M., Haponen, I. \& Hänninen, M. I. (1997). Helicobacter salomonis sp. nov., a canine gastric Helicobacter sp. related to Helicobacter felis and Helicobacter bizzozeronii. Int J Syst Bacteriol 47, 975-982.

Kusters, J. G., Gerrits, M. M., Van Strijp, J. A. G. \& Vandenbroucke-Grauls, C. M. J. E. (1997). Coccoid forms of Helicobacter pylori are the morphologic manifestation of cell death. Infect Immun 65, 3672-3679.

Lee, A., Phillips, M. W., O'Rourke, J. L. \& 7 other authors (1992). Helicobacter muridarum sp. nov., a microaerophilic helical bacterium with a novel ultrastructure isolated from intestinal mucosa of rodents. Int J Syst Bacteriol 42, 27-36.

Marchini, A., d'Apolito, M., Massari, P., Atzeni, M., Copass, M. \& Olivieri, R. (1995). Cyclodextrins for growth of Helicobacter pylori and production of vacuolating cytotoxin. Arch Microbiol 164, 290-293.

Moran, A. P. (1997). Coccoid forms of Helicobacter pylori. Helicobacter 2, 109-110.

Moran, A. P. \& Upton, M. E. (1986). A comparative study of the rod and coccoid forms of Campylobacter jejuni ATCC 29428. J Appl Bacteriol 60, 103-110.

Moran, A. P. \& Upton, M. E. (1987a). Effect of medium supplements, illumination and superoxide dismutase on the production of coccoid forms of Campylobacter jejuni ATCC 29428. J Appl Bacteriol 62, 43-51.

Moran, A. P. \& Upton, M. E. (1987b). Factors affecting production of coccoid forms by Campylobacter jejuni on solid media during incubation. J Appl Bacteriol 62, 527-537.

Narikawa, S., Kawai, S., Aoshima, H., Kawamata, O., Kawaguchi, R., Hikiji, K., Kato, M., lino, S. \& Mizushima, Y. (1997). Comparison of the nucleic acids of helical and coccoid forms of Helicobacter pylori. Clin Diagn Lab Immunol 4, 285-290.

Nilsson, H.-O., Taneera, J., Castedal, M., Glatz, E., Olsson, R. \& Wadström, T. (2000a). Identification of Helicobacter pylori and other Helicobacter species by PCR, hybridization and partial 
DNA sequencing in human liver samples from patients with primary sclerosing cholangitis or primer biliary cirrhosis. J Clin Microbiol 38, 1072-1076.

Nilsson, I., Lindgren, S., Eriksson, S. \& Wadström, T. (2000b). Serum antibodies to Helicobacter hepaticus and Helicobacter pylori in patients with liver disease. Gut 46, 410-414.

Norris, C. R., Marks, S. L., Eaton, K. A., Torabian, S. Z., Munn, R. J. \& Solnick, J. V. (1999). Healthy cats are commonly colonized with Helicobacter heilmannii that is associated with minimal gastritis. J Clin Microbiol 37, 189-194.

Roberton, A. M. \& Stanley, R. A. (1982). In vitro utilization of mucin by Bacteroides fragilis. Appl Environ Microbiol 43, 325-330.

Shahamat, M., Mai, H. E. U., Paszko-Kolva, C., Yamamoto, H. \& Colwell, R. R. (1991). Evaluation of liquid media for growth of Helicobacter pylori. J Clin Microbiol 29, 2835-2837.

Signoretto, C., del Mar Lleo, M., Tafi, M. C. \& Canepari, P. (2000). Cell wall chemical composition of Enterococcus faecalis in the viable but non-culturable state. Appl Environ Microbiol 66, 1953-1959.

Soltesz, V. L. \& Mårdh, P. (1980). Serum free liquid media for Neisseria gonorrhoeae. Curr Microbiol 4, 45-49.

Soltesz, V., Zeeberg, B. \& Wadström, T. (1992). Optimal survival of Helicobacter pylori under various transport conditions. J Clin Microbiol 30, 1453-1456.

Stanley, J., Linton, D., Burnens, A. P., Dewhirst, F. E., On, S. L.,
Porter, A., Owen, R. J. \& Costas, M. (1994). Helicobacter pullorum sp. nov., genotype and phenotype of a new species isolated from poultry and from humans with gastroenteritis. Microbiology 140, 3441-3449.

Versalovic, J. \& Fox, J. G. (2001). Taxonomy and phylogeny of Helicobacter. In Helicobacter pylori: Molecular and Cellular Biology, pp. 15-28. Edited by M. Achtman \& S. Suerbaum. Wymondham, Norfolk, England: Horizon Scientific Press.

Walsh, E. J. \& Moran, A. P. (1997). Influence of medium composition on the growth and antigen expression of Helicobacter pylori. J Appl Microbiol 83, 67-75.

Ward, J. M., Fox, J. G., Anver, M. B., Haines, D. C., George, C. V. \& Collins, M. L. (1994). Chronic active hepatitis and associated liver tumours in mice caused by persistent bacterial infection with a novel Helicobacter species. J Natl Cancer Inst 86, 1222-1227.

West, A. P., Millar, M. R. \& Tompkins, D. S. (1990). Survival of Helicobacter pylori in water and saline. J Clin Pathol 43, 409.

Worku, M. L., Sidebotham, R. L., Walker, M. M., Keshavarz, T. \& Karim, Q. N. (1999). The relationship between Helicobacter pylori motility, morphology and phase of growth: implications for gastric colonization and pathology. Microbiology 145, 28032811.

Received 26 June 2001; revised 9 November 2001; accepted 15 November 2001. 